\title{
The Transitional Heart: From Early Embryonic and Fetal Development to Neonatal Life
}

\author{
Cheryl Mei Jun Tan Adam James Lewandowski \\ Oxford Cardiovascular Clinical Research Facility, Division of Cardiovascular Medicine, Radcliffe \\ Department of Medicine, University of Oxford, Oxford, UK
}

\section{Keywords}

Cardiac development · Transitional physiology .

Fetal heart $\cdot$ Neonatal heart $\cdot$ Developmental biology

\begin{abstract}
Formation of the human heart involves complex biological signals, interactions, specification of myocardial progenitor cells, and heart tube looping. To facilitate survival in the hypoxemic intrauterine environment, the fetus possesses structural, physiological, and functional cardiovascular adaptations that are fundamentally different from the neonate. At birth, upon separation from the placental circulation, the neonatal cardiovascular system takes over responsibility of vital processes for survival. The transition from the fetal to neonatal circulation is considered to be a period of intricate physiological, anatomical, and biochemical changes in the cardiovascular system. With a successful cardiopulmonary transition to the extrauterine environment, the fetal shunts are functionally modified or eliminated, enabling independent life. Investigations using medical imaging tools such as ultrasound and magnetic resonance imaging have helped to define normal and abnormal patterns of cardiac remodeling both in utero and ex utero. This has not only allowed for a better understanding of how congenital cardiac malforma-
\end{abstract}

tions alter the hemodynamic transition to the extrauterine environment but also how other more common complications during pregnancy including intrauterine growth restriction, preeclampsia, and preterm delivery adversely affect offspring cardiac remodeling during this early transitional period. This review article describes key cardiac progenitors involved in embryonic heart development; the cellular, physiological, and anatomical changes during the transition from fetal to neonatal circulation; as well as the unique impact that different pregnancy complications have on cardiac remodeling.

(c) 2019 The Author(s) Published by S. Karger AG, Basel

\section{Introduction}

The human heart is one of the first organs to form and function during embryogenesis $[1,2]$. By the end of gestational week 3 , passive oxygen diffusion becomes insufficient to support metabolism of the developing embryo [35], and thus the fetal heart becomes vital for oxygen and nutrient distribution [2]. The initiation of the first heart beat via the primitive heart tube begins at gestational day 22 , followed by active fetal blood circulation by the end of week $4[1,3-5]$. The start of early heart development involves sev- 


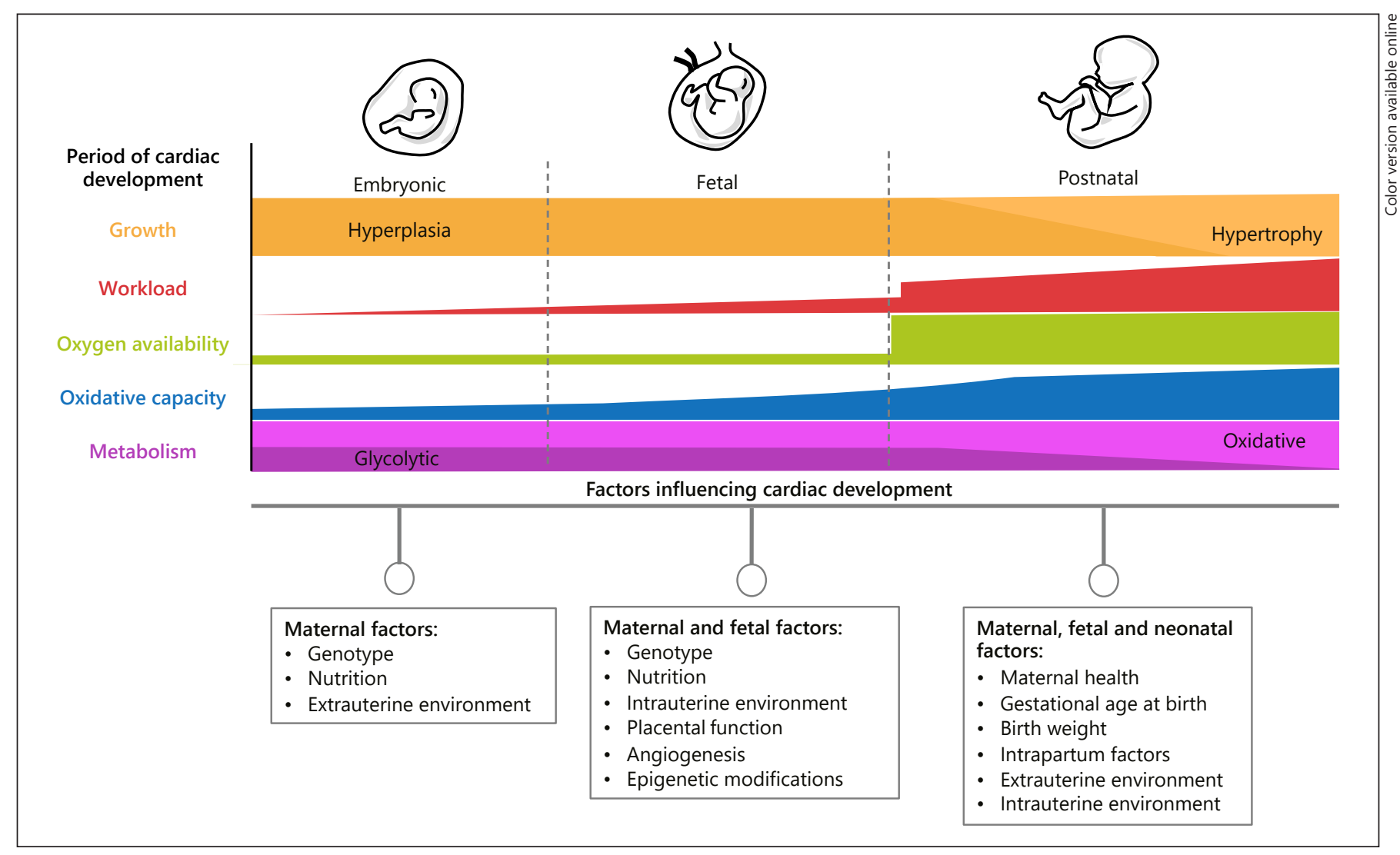

Fig. 1. Cardiac development during embryonic, fetal, and neonatal life and the influence of maternal, fetal, and neonatal factors.

eral types of progenitor cells that are derived from the mesoderm, proepicardium, and neural crest. This eventually leads to the formation of the 4-chambered heart by gestational week 7 via heart looping and complex cellular interactions in utero [2]. Intrauterine fetal life is sustained in a secure, isolated, and hypoxemic environment that is dependent on the mother's placenta for nutrition, respiration, waste elimination, and metabolism [6]. To facilitate survival in the hypoxemic intrauterine environment, the fetus possesses structural, physiological, and functional cardiovascular adaptations that are fundamentally different from the neonate [3, 4]. At birth, upon separation from the placental circulation, the neonatal cardiovascular system takes over responsibility of vital processes [6].

The transition from intrauterine to extrauterine life requires well-orchestrated and complex biochemical, physiological, and anatomical changes in a timely manner to ensure neonatal survival [4]. However, any disruption in early development and transition can have long lasting, adverse, and sometimes fatal consequences (Fig. 1). While it is well known that congenital cardiac malformations alter the hemodynamic transition to the extrauterine environ- ment, other more common complications during pregnancy including intrauterine growth restriction (IUGR), prematurity, and preeclampsia have also been shown to adversely affect offspring cardiac remodeling before, during, and after the transitional period [7-10]. Imaging tools such as ultrasonography and magnetic resonance imaging (MRI) throughout pregnancy and early postnatal life provide detailed information about fetal and neonatal cardiovascular health and can assist in identification of potential hemodynamic abnormalities and adverse cardiac remodeling $[4,11]$. This review article highlights important cellular, physiological, and anatomical adaptations involved in the transition from fetal to neonatal circulation, as well as the transitional perturbations caused by congenital cardiac malformations and pregnancy complications.

\section{Early Cardiac Development}

\section{Cellular Aspects of Early Cardiogenesis}

A cascade of transcription factor activation ultimately results in cardiac specification. Transcription factors me- 
soderm posterior 1 and $2($ MESP $1 / 2)$ are the earliest markers of cardiovascular specification and are expressed at the start of gastrulation $[12,13]$. MESP1 represses pluripotent-inducing genes and drives expression of cardiac transcription factors [14]. As cardiac precursors migrate away from the primitive streak to form the cardiac crescent, MESP $1 / 2$ is downregulated while activating other transcription factor networks that drive cardiac specification. Early heart development involves myocardial progenitor cells, including first heart field (FHF) and second heart field (SHF) progenitor cells, as well as proepicardial progenitor cells derived from the lateral plate mesoderm and ectoderm-derived cranial neural crest cells (Fig. 2a). These cells emerge via the interaction of inductive and inhibitory signals from the germ layers (endoderm, mesoderm, and ectoderm) during gastrulation [2, 15, 16]. Molecular signals include cardiac differentiation inhibitors (i.e., wingles integrated, Wnt) and cardiac differentiation inducers (i.e., fibroblast growth factor, FGF and bone morphogenetic proteins, BMPs) [16-20]. Disruption in Wnt $/ \beta$-catenin signaling in endoderm via deletion of $\beta$-catenin results in the formation of ectopic cardiac tissue in the overlying mesoderm [21].

\section{Formation of Cardiac Chambers: Heart Tube \\ Formation and Looping}

The specification and differentiation of progenitor cells via specific heart fields are critical for embryonic heart development $[2,22]$. During the second week of human gestation, the cardiac mesodermal cells migrate toward the anterior direction of the embryo to form the 2 major cardiac progenitor pools: the earliest cells to express MESP1 form the FHF or cardiac crescent and the later wave of MESP1 produces cells that form the SHF (located posterior to the crescent; Fig. 2b) [1, 16, 22, 23]. Both FHF and SHF express specific transcription factors and are the main reservoirs for cardiomyocytes, where mononucleated cardiomyocytes undergo hyperplasia in order to increase cell number for cardiac growth $[1,2,16$, $22,24,25]$.

The specification of cardiac chamber morphogenesis is modulated by several transcription factors, including T-box transcription factors TBX2, TBX3, TBX5, and TBX20; as well as NKX2-5, GATA4, and HAND1 [13]. GATA4 and NKX2-5 in combination with TBX5 and TBX20 promote myocardial specification via the expression of chamber myocardium-specific genes including induction of atrial natriuretic factor, gap junction protein connexins 40/43, and transcriptional repressor ID2, which improves contractibility and patterning of the

The Fetal and Neonatal Heart right ventricular (RV) and left ventricular (LV) bundle branches [25-28]. BMP-induced BX2/3 expression is involved in non-chamber myocardial specification including the atrioventricular canal, outflow and inflow tract [29]. TBX20, an inhibitor of BMP-induced TBX2/3 activation, is broadly expressed throughout the linear heart tube to ensure chamber myocardium specification. Deletion of TBX20 results in defects in chamber development [30]. Furthermore, disturbance of morphogenetic transcription and growth factors including TBX1, TBX5, GATA4, and BMP4 within the SHF-derived cell populations may result in a spectrum of ventricular septal defects at the outflow tract [31]. Ventricular septal defects are characterized by membranous ventricular septum via the fusion of the endocardial outflow tract and atrioventricular canal, which allows blood to pass form the left-toright side of the heart [32]. If significant in size and unrepaired postnatally, they can result in elevation in pulmonary vascular resistance (PVR), pulmonary arterial pressure, hypoxia, and cyanosis [33].

The SHF of the human embryo shows a dynamic spatio-temporal distribution pattern [34]. During the third week, the FHF fuses at the midline to form the primitive heart tube, which starts to beat at around embryonic day 22 and eventually gives rise to the LV and parts of the right and left atria $[2,16,22,24]$. Blood flow and contraction causes peristaltic pumping motion in the linear heart tube, which may contribute to the ballooning process since endocardial and myocardial cells alter their shape, size, and proliferation in response to mechanical stress [35-37]. Subsequently, during week 4, the heart tube undergoes rightward looping, with its posterior region moving anteriorly $[2,15,16,23,38]$. SHF progenitors, located behind the primary heart tube within the pharyngeal mesoderm, migrate toward the primitive and looping heart tube, contributing to the RV, parts of the atria, septum and outflow tract, and later to the base of the aorta and pulmonary trunk $[16,34]$. The cells from the venous poles contribute to the base of the superior and inferior vena cava (SVC and IVC, respectively) [16].

Cardiac trabeculation occurs after the cardiac looping, it promotes the formation of luminal projections (trabeculae), which consist of myocardial cells enclosed by the endocardial layer [39]. Trabeculation and subsequent compaction of the ventricular myocardium facilitates septation, increases cardiac output, contractility and conductivity, and helps establish the coronary circulation system in the developing heart [39-44]. NOTCH1 regulates trabecular growth via promoting endothelial growth factor neuregulin-1 activity through endocardial Ephrin B2 [41]. 


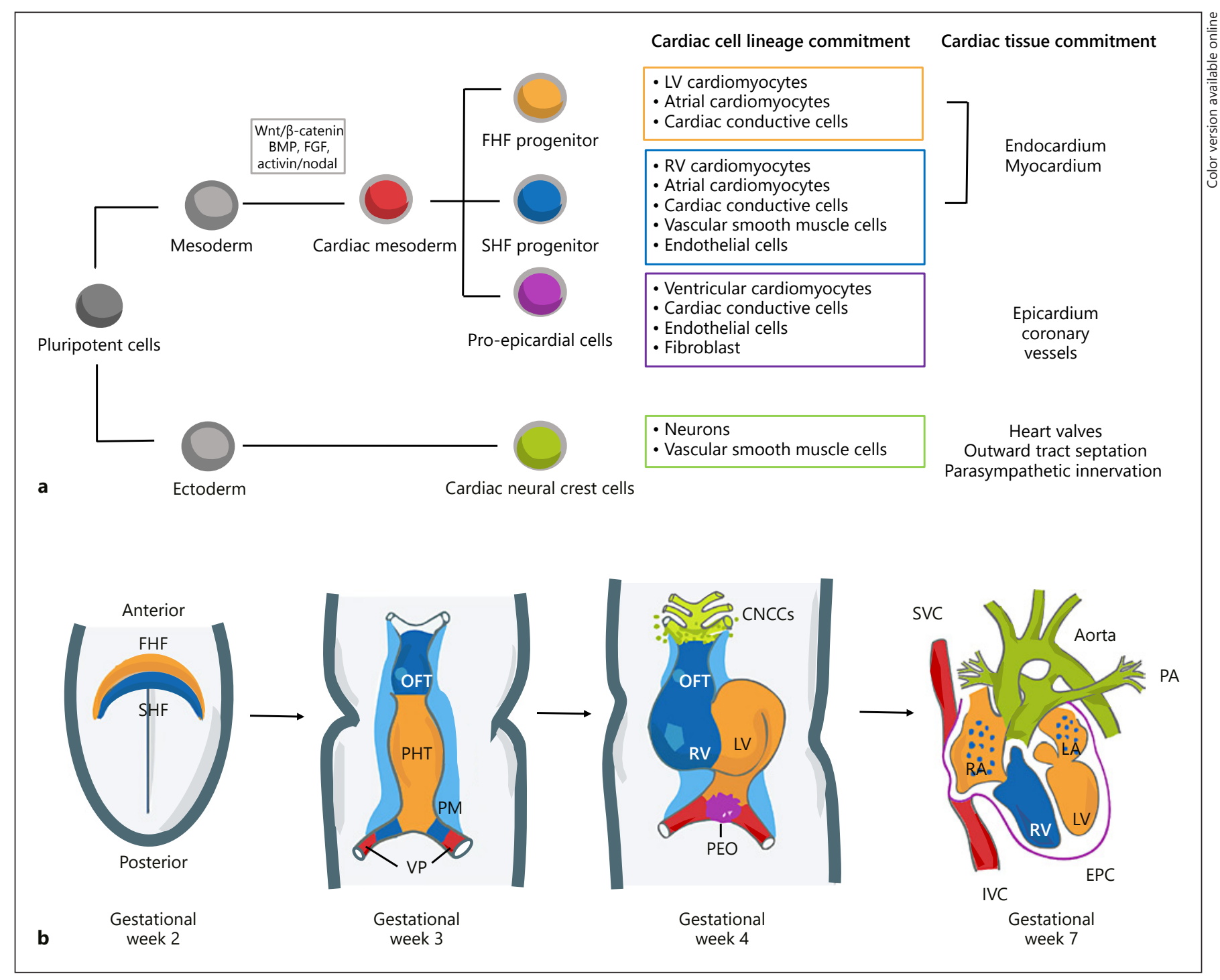

Fig. 2. Early cardiac development. a Cardiac cell lineage and specification during development demonstrating the commitment of pluripotent cells toward mature cardiac cell types within the heart development. b Schematic of cardiac morphogenesis in humans. At the second week of gestation, the cardiogenic mesodermal cells migrate toward the anterior side of the embryo to form the FHF or cardiac crescent and SHF that are specified to form specific segments of the PHT, which is patterned along the anteroposterior axis to form the various regions and chambers of the looped and mature heart during weeks 3 and 4 . The FHF gives rise to the beating PHT and will eventually give rise to the LV and parts of the right and left atria (RA and LA, respectively). The SHF, located behind the PHT and within the pharyngeal mesoderm by gestational week 3 , will contribute to the formation of the RV, parts of the atria and outflow tract, and later to the base of the aorta and pulmonary artery. At gestational week 3, the cells at the venous pole contribute to the formation of the superior and inferior vena cavas (IVC, respectively). By gestational week 4, the cardiac neural crest cells migrate in from the dorsal neural tube, forming smooth muscle cells within the aortic and pulmonary arteries. In addition, the proepicardial organ formed by the proepicardial progenitor cell clusters later contributes to the formation of the epicardium. The 4 chambers form by the end of week 7 . Wnt, Wingles integrated; FGF, fibroblast growth factor; BMP, bone morphogenetic proteins; FHF, first heart field; SHF, second heart field; OFT, outflow tract; PHT, primary heart tube; PM, pharyngeal mesoderm; VP, venous pole; CNCCs, cardiac neural crest cells; LV, left ventricle; RV, right ventricle; $\mathrm{PEO}$, proepicardial organ; SVC, superior vena cavas; IVC, inferior vena cavas; EPC, epicardium; and PA, pulmonary artery. 
The neuregulin-1 protein binds to the myocardial tyrosine kinase receptor erbB-4 (ERBB4) and dimerizes with ERBB2, thereby activating signaling cascades that modulate cell migration and proliferation. Mutations in ERBB2 result in compromised ventricular contraction [45].

\section{Formation of the Epicardium, Heart Valves, and}

Parasympathetic Innervation

The embryonic pro-epicardial progenitor cells located at the celomic mesenchyme of the septum transversum will differentiate into cardiac fibroblasts, coronary vasculature, and a small number of cardiomyocytes, which eventually form the outer lining of the (epicardium) [1, $16,46]$. The fourth progenitor population involved in human embryonic cardiogenesis consists of the cranial neural crest cells, which migrate in from the dorsal neural tube through the pharyngeal arches via stromal cell-derived factor 1 as a chemotactic agent $[16,22,47]$. The neural crest cells are involved in septation of the outflow tract and the formation of heart valves, with NOTCH1 contributing to heart valve formation. Several gene mutations in NOTCH1 have now been reported in the human population to be associated with bicuspid aortic valve [32]. Neural crest cells also give rise to smooth muscle cells within aortic and pulmonary arteries, along with the full autonomic and sensory innervation of the heart $[16$, 22 ]. Anomalies in the cardiac neural crest are responsible for a multitude of human cardio-cranio-facial defects, such as DiGeorge syndrome, which is associated with TBX1 deletion $[48,49]$. Through the looping process, complex interactions of FHF and SHF progenitors, as well as pro-epicardial and cranial neural crest cells, the fetal heart is septated into 4 defined cardiac chambers, which connect to the aorta and pulmonary trunk around gestational week $7[2,16,22]$.

\section{The Fetal Cardiovascular System}

The fetal cardiovascular system is adapted biochemically and structurally to ensure that the highly oxygenated blood is delivered preferentially from the placenta to the brain and the heart while being diverted away from the lungs. The combination of the following contributes to the maintenance of the fetal cardiovascular system: (i) biochemical factors, including vasoregulatory agents such as prostaglandins and endothelin-1 and (ii) anatomical adaptations, such as the presence of 4 shunts: the placenta, ductus venosus (DV), ductus arteriosus (DA), and foramen ovale (FO; Fig.3a) [6, 50-52].

The Fetal and Neonatal Heart
Fetal Biochemical Adaptations: Upregulation of

\section{Vasoconstrictors}

Endothelin-1 plays a key role in utero-placental circulation by aiding the maintenance of high PVR in the fetal circulation [53, 54]. Expression of vasoconstrictive prostaglandin F2 $\alpha$ during early gestation has also been observed to maintain the high PVR, while there is an increase in vasodilating prostaglandin $\mathrm{I} 2$ and $\mathrm{E} 2\left(\mathrm{PGI}_{2}\right.$ and $\mathrm{PGE}_{2}$, respectively) nearer to term to aid in the fetal to neonatal transition [5].

\section{Fetal Structural Adaptations: The Four Shunts in \\ Fetal Circulation}

By the 10th week of gestation, the fetal circulation has transitioned from passive gas exchange by both the yolk sac and the placenta to being placenta dominant (Fig. 3a) [4]. The placenta is not only the source of nutrition but also an organ of waste elimination for the fetus; the supply of nutrients, as well as the exchange of oxygen and waste products, takes place in the intervillous space [6]. It is a low resistance vascular bed, which promotes the fetalto-maternal exchange of deoxygenated blood under low pressure $[3,50]$. Despite the low partial pressure of oxygen in the placenta, oxygen delivery to fetal tissues remains adequate due to the combined high ventricular output and the presence of fetal hemoglobin, which has a higher oxygen affinity than adult hemoglobin $[50,55,56]$.

Following oxygenation in the intervillous spaces, relatively oxygenated fetal blood is carried by the umbilical vein to the liver $[5,57]$. The DV allows $50-60 \%$ of umbilical vein blood to bypass the hepatic circulation and enter the IVC, mixing with desaturated IVC blood $[6,58]$. The remainder of blood perfuses the liver, ultimately merging with desaturated blood from the lower part of the body via the IVC to enter the right atrium [6]. In the right atrium, blood is diverted into 2 streams, with more than half traversing the FO in the inter-atrial septum to enter the left atrium $[23,50,51,59]$. This oxygen saturated blood then passes through the LV and mixes with the pulmonary venous return to be pumped through the ascending aorta toward the carotid and coronary arteries $[5,23,50,60]$. The remainder of IVC blood flow mixes with desaturated blood from the superior vena cava, which first enters the RV through the tricuspid valve and, subsequently, the pulmonary artery $[5,57]$. The high PVR results in the majority of blood that leaves the RV being preferentially shunted through the DA, bypassing the pulmonary circulation and going directly into the descending aorta. As a result, only $8-10 \%$ of total cardiac output passes through the high-resistance pulmonary cir- 


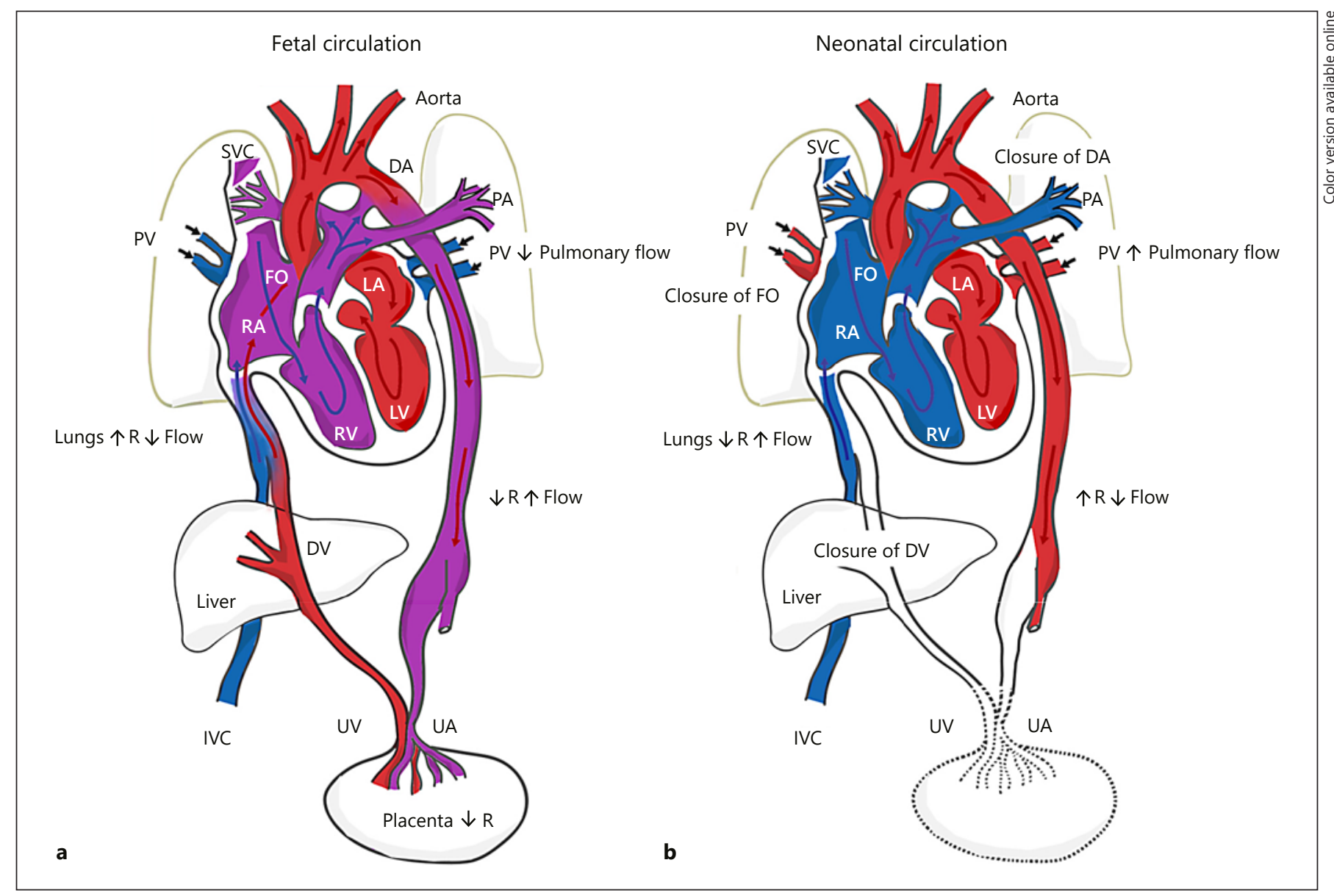

Fig. 3. Schematic of normal fetal and neonatal cardiovascular circulation. a During fetal development, oxygenated and nutrientrich fetal blood from the placenta passes to the fetus via the umbilical vein. Approximately half of this blood bypasses the liver via the DV and enters the IVC. The remainder enters the portal vein to supply the liver with nutrients and oxygen. Blood entering the RA from the IVC bypasses the RV as the lungs are not yet functioning, and then enters the LA via the FO. Blood from the SVC enters the RA, passes to the RV, and moves into the PA trunk. Most of this blood enters the aorta via the DA, a right-to-left shunt. The partially oxygenated blood in the aorta returns to the placenta via the paired UA that arise from the internal iliac arteries. b Under normal physiological conditions, when pulmonary respiration be-

culation $[5,50,57,59,61,62]$. Approximately $40-60 \%$ of blood that enters the descending aorta either supplies the umbilical artery to the lower limbs or is reoxygenated at the placenta [57].

\section{Fetal Combined Ventricular Output and Heart Rate}

Normal fetal heart rate ranges from 110 to 160 beats per minute (Table 1) [63], with the low resistance placental bed providing a low systemic vascular resistance (SVR) gins at birth, pulmonary blood pressure falls, causing blood from the main PA trunk to enter the left PA and right PA, become oxygenated at the lungs, and then return to the LA via the PV. The FO and DA close, eliminating the fetal right-to-left shunts. The pulmonary and systemic circulations in the heart are now separate. As the infant is separated from the placenta, the UAs occlude (except for the proximal portions), along with the umbilical vein and DV. Blood to be metabolized now passes through the liver. DV, ductus venosus; UV, umbilical vein; IVC, inferior vena cava; RA, right atrium; RV, right ventricle; LA, left atrium; FO, foramen ovale; SVC, superior vena cava; PA, pulmonary artery; DA, ductus arteriosus; $\mathrm{UA}$, umbilical arteries; $\mathrm{PV}$, pulmonary veins.

and absorbing over $40 \%$ of the combined cardiac output from both ventricles [6]. Increased PVR combined with low SVR results in the right-to-left shunting of blood through the FO and the patent ductus arteriosus (PDA), with the RV accounting for two-thirds of cardiac output perfusing the lower half of the body and placenta. LV output is directed toward the coronary and carotid arteries, supplying the heart muscle wall and brain $[51,57,64-66]$. The amount of blood entering the pulmonary circulation 
Table 1. Differences between fetal and postnatal circulations

\begin{tabular}{|c|c|c|c|c|c|c|}
\hline Fetal & Parallel & Placenta & $\mathrm{DV}, \mathrm{DA}, \mathrm{FO}$ & $470-500$ & $110-160$ & Pulmonary $>$ systemic \\
\hline Neonatal & Series & Lungs & $\begin{array}{l}\text { Closure of shunts: } \\
\text { DV } \rightarrow \text { Ligamentum venosum } \\
\text { DA } \rightarrow \text { Ligamentum arteriosum } \\
\text { FO } \rightarrow \text { Fossa ovalis }\end{array}$ & 200 & $100-120$ & Systemic $>$ pulmonary \\
\hline
\end{tabular}

DV, ductus venosus; DA, ductus arteriosum; FO, foramen ovale.

varies during pregnancy, increasing from just over $10 \%$ of the combined cardiac output at mid-gestation to around $25 \%$ by 30 weeks' gestation [5]. Perfusion rate of fetal tissues is higher than in the adult, with normal ranges of $470-500 \mathrm{~mL} / \mathrm{kg} / \mathrm{min}$ measured by Doppler ultrasound (Table 1) [64].

\section{The Transition to Neonatal Circulation}

The neonatal period involves dramatic and rapid physiological changes [57]. The transition to the postnatal environment triggers cardiomyocytes to switch from a fetal hyperplastic (cell proliferation) to hypertrophic (increase in cell size) growth pattern $[67,68]$. Hypertrophy of cardiomyocytes is achieved via karyokinesis without cytokinesis (mitotic cell division without cytoplasmic separation), resulting in the formation of binucleated myocardial cells to promote myocardial growth [69-71]. As such, in the first few months of postnatal life, myocardial cell volume increases approximately 30 -fold in humans. Cardiopulmonary adaptation at birth involves an intricate series of timely biochemical and structural modifications that are required for a successful cardiopulmonary transition from the fetal to neonatal circulation, which includes a switch in the site of gas exchange from the placenta to the neonatal lungs [6].

\section{Neonatal Biochemical Adaptations}

Changes in the activity of cyclo-oxygenase appear to be involved in adaptation to the extrauterine environment [5]. After birth, there is an inhibition of cyclo-oxygenase- 2 enzyme pathways, which results in a reduction of the vasoconstrictor thromboxane. After the third trimester, there is an upregulation of endothelial nitric oxide (NO) synthase, which results in greater synthesis of the vasodilator NO. As a direct consequence of the increased oxygenation associated with lung inflation, there is also a surge in NO at birth $[5,59]$. NO causes smooth muscle relaxation and arteriolar vasodilation, leading to lower PVR [59]. Vasodilation is further encouraged by the increased secretion of vasodilating $\mathrm{PGI}_{2}$ and $\mathrm{PGE}_{2}$ [6].

Acute adaptations to postnatal life are also managed by catecholamine release [52]. During delivery, there is a surge in circulating catecholamines, which act to strengthen myocardial contractility and increase heart rate. This leads to sufficient elevation of cardiac output in order to meet the increased metabolic demands associated with spontaneous thermogenesis, feeding, and breathing [52, 57]. With increasing gestation, fetal cortisol and thyroxine levels also rise gradually until term gestation, further increasing during labor and peaking just after birth [52]. Cortisol is important for maturation of pulmonary surfactant, increasing catecholamine secretion, as well as increasing the density of vasodilatory $\beta$-adrenoreceptors in the heart and lungs [52]. Furthermore, both cortisol and thyroxine activate sodium pumps within the alveoli to facilitate lung fluid removal.

\section{Neonatal Structural Adaptations: Neonatal Circulation and Modified Shunts}

The transition from fetal to postnatal circulation requires the removal or modification of the 4 fetal shunts (placenta, DV, DA, FO) to eliminate the umbilico-placental circulation, resulting in a large increase in SVR (Fig. 3b, Table 1) [51, 52, 61]. As SVR rises and stabilizes, PVR declines and the right-to-left shunt through the DA reverses to become a left-to-right shunt. RV output is also directed fully to the pulmonary circulation, leading to an increase in biventricular stroke volume [51, 61, 72-74]. Any perturbations to the transitional process may result in neonatal cardiopulmonary dysfunction. For instance, 
failure for normal postnatal PVR reduction results in an inefficient right-to-left shunting with resultant pulmonary vasoconstriction, hypoxemia, and acidosis. This can lead to persistent pulmonary hypertension of the newborn (PPHN) [33, 75]. PPHN is the most common form of pediatric pulmonary hypertension and can lead to organ failure in severe cases [75]. The pathogenesis of PPHN includes: (i) cardiovascular maladaptation presented in neonates with normal pulmonary vascular morphology but increased vascular reactivity and impaired vasodilation (sepsis, asphyxia, pneumonia, or respiratory distress syndrome); (ii) cardiovascular maldevelopment, including morphologically abnormal pulmonary vasculature observed in lung hypoplasia and idiopathic PPHN; and (iii) structurally abnormal heart diseases causing LV outflow tract obstruction, such as critical aortic stenosis and interrupted aortic arch $[33,75]$.

Cutting the umbilical cord eliminates the low-resistance placental flow and stimulates peripheral and central chemoreceptors, which combined with other factors (thermal, neuroendocrine, and mechanical stimuli), contributes to the onset and maintenance of neonatal respiratory efforts. A subsequent increase in SVR and reduction in right heart preload results [6], with the SVR continuing to increase due to cold stress and catecholamine surges [76]. Initiation of breathing stimulates a series of events that are responsible for the shift from fetal to postnatal circulatory patterns. Hypoxemia can occur in the neonatal period via ventilation/perfusion mismatch, hypoventilation (impaired ventilatory function and reduced respiratory compliance), inadequate pulmonary surface area (i.e., pulmonary hypoplasia, diaphragmatic hernia), and increased physiological dead space, including respiratory distress syndrome [75].

Fetal production of lung fluid decelerates shortly before full-term birth, with labor providing a strong driving force for lung fluid removal $[3,52,59]$. With the resorption and removal of lung fluid from the alveoli, surfactant secretions by type II pneumocytes into the acinus support the retention of the first breaths of air into the newly inflated lung [52]. Lung aeration allows the establishment of alveolar surface tension, as well as negative interstitial and intrapleural pressures, thereby increasing the alveolar partial pressure of oxygen and oxygen saturation [50]. After initial lung inflation, PVR decreases rapidly, and $\mathrm{RV}$ cardiac output begins to flow predominantly through the pulmonary artery into the lungs, increasing pulmonary blood flow and pulmonary venous return to the left atrium resulting in a left-to-right shunt direction and higher left atrial pressures [3, 52, 59, 77, 78]. This causes the displacement of the flap of the FO over the rims of the fossa and stops the right-to-left flow [79]. Functional closure of the FO is brought about soon after birth (minutes to hours). However, left-to-right flow through the FO can commonly be seen for a few days as the circulation readjusts [80]. This results in left atrial pressure rising as pulmonary venous return increases and left-to-right shunting of blood at the atrial level is diminished [52]. Anatomic closure of the FO usually occurs by 3 months of age, with up to $50 \%$ complete closure by age 5 years $[23,51$, 57]. It remains probe patent in $30 \%$ of adults, which, in cases of pulmonary hypertension and a rise in right atrial pressure, can facilitate a paradoxical embolus and potential stroke [57].

The physiological transition to the extrauterine environment increases the systemic arterial oxygen tension, and the decrease in circulating $\mathrm{PGE}_{2}$ (including placental prostaglandins) promotes the constrictive effect of oxygen on the ductal tissue $[50,52,81,82]$. Furthermore, endothelin-1 constricts the DA in response to oxygen [50, 61]. In term-born babies, functional closure of the DA commences immediately after the umbilical cord is cut and may take between 1 and 4 days [23]. Over the subsequent 4-8 weeks, permanent anatomical closure occurs via endothelial proliferation and fibrosis, giving rise to the ligamentum arteriosum [80]. In some term infants and many preterm infants, the process of physiologic ductal closure can be maladaptive, delayed, or even arrested [80]. If the situation is considered hemodynamically significant, medical therapy will be required to augment closure of the DA, with possible surgical ligation depending on severity [80]. Despite closure (either spontaneously or with medical therapy), the hemodynamic environment may induce DA opening and the persistence of the DA can have deleterious hemodynamic consequences [83]. Immediately after birth, the DV ceases to function, resulting in complete perfusion of the liver and reduction in blood returning to the IVC. However, the structural closure may take between 3 and 7 days in a term-born baby $[52,84]$. The structure disappears within 2 weeks after birth and ultimately becomes the ligamentum venosum [23].

Echocardiography studies of healthy term neonates have expanded our understanding of the transitional physiology and hemodynamics $[72,74]$. These studies have revealed that on day 2 postpartum, there is a small reduction in LV basal diameter, mitral valve inflow velocity time integral, and systolic velocity of the lateral wall and septum [72]. On the other hand, there is a small increase on day 2 of life in RV dimensions including mid- 
cavity diameter, RV antero-inferior basal diameter, and end-diastolic area. The differential adaptive physiological responses of the RV and LV, pulmonary hemodynamics, and shunt characteristics may relate to loading conditions and patent DA closure $[72,73]$. Any perturbations to the transition process may result in dysfunction in neonatal cardiopulmonary function.

\section{Neonatal Cardiac Output, Heart Rate, and Blood}

Pressure

With the functional closure of FO and DA, output from the ventricles equalizes and overall cardiac output increases by nearly double $[51,61]$. The increase gradually returns to lower levels within the first $24 \mathrm{~h}$ [52]. At term, the neonatal cardiac output is approximately $200 \mathrm{~mL} / \mathrm{kg} / \mathrm{min}$ [85], which is more than twice that of adults relative to body weight [57]. However, the neonatal myocardium is stiffer with fewer myofibrils in a more disordered arrangement, with a low arterial systolic and diastolic blood pressure of 60 and $30 \mathrm{~mm} \mathrm{Hg}$, respectively. Based on the Frank-Starling relationship, this leads to a limited increase in stroke volume for a given ventricular filling volume $[57,86]$. Thus, the neonatal myocardium is initially more dependent on heart rate to increase cardiac output, with heart rates around $160-180$ beats per minute in the first $30 \mathrm{~min}$ following delivery and then stabilizing in the range of $100-160$ beats per minute (Table 1) $[6,57]$. Shortly thereafter, the LV hypertrophies as it takes over the systemic circulation and the RV remodels to being the thin-walled, crescent shaped chamber that supplies the lower pressure pulmonary circulation [3]. By 3 weeks' postnatal age, pulmonary pressure has normally fallen below systemic pressure and by 3-6 months after birth, the classical LV dominant pattern of adulthood is established with increased SVR-stimulating ventricular hypertrophy [57].

\section{Impact of Pregnancy Complications on Early Cardiac Remodeling}

A number of clinical conditions and diseases exist that can affect transitional physiology and lead to longterm cardiovascular health complications, such as congenital heart diseases. While the full discussion of these diseases and conditions is beyond the scope of this review, herein we have focused on more common complications that affect transitional physiology and have been identified as novel long-term cardiovascular risk factors.

The Fetal and Neonatal Heart

\section{Intrauterine Growth Restriction}

IUGR fetuses do not grow according to their genetic growth potential, which can be caused by impaired placentation including utero-placental vascular insufficiency $[7,87]$. When over a third of the fetal villous vasculature is abnormal, the Doppler resistance indices indicate an increase in impedance to flow and resistance in the umbilical artery [88]. In severe cases, where $>60 \%$ of the villous tree is damaged, it may couple with absent enddiastolic flow or reversed end-diastolic flow, promoting fetal distress when the gaseous exchange in the intrauterine environment has deteriorated [88-91]. In monochorionic twins, selective IUGR may occur, which is when unequal sharing of the placental mass results in poor fetal growth in one of the twins [92]. The use of fetal ultrasound allows for identification of the velocity, direction, and patterns of blood flow to diagnose selective IUGR, as well as to differentiate it from twin-twin transfusion syndrome. Unlike selective IUGR, in twin-twin transfusion syndrome, there is a large inequality in blood sharing between the monochorionic twins via placental blood vessel connections, such that one twin acts as the donor and the other as the recipient. This results in changes in urine output and amniotic fluid volume, which can lead to fetal hydrops in the recipient due to volume overload [92].

IUGR offspring demonstrate early cardiac changes that emerge during fetal life and persist into neonatal life, including a relatively hypertrophied ventricular septum, LV dilatation, decreased myocardial reserve, a more globular cardiac morphology, and abnormal early postnatal hemodynamic adaptations [8, 93-95]. Furthermore, IUGR neonates exhibit an increase in left myocardial performance index (a marker of ventricular dysfunction), an inability to increase LV stroke volume, as well as reduced heart rate in the first week of postnatal life when compared with appropriate-for-gestational-age controls $[8$, 96]. Changes in cardiomyocyte functionality including altered contractile machinery in the form of shorter sarcomere length and delayed cardiomyocyte maturation may help to explain the cardiac dysfunction associated with IUGR $[97,98]$. It is likely that these early changes are of long-term clinical significance, given that epidemiologic studies have consistently shown an association between IUGR and an increased rate of cardiovascular mortality in adulthood [99]. In line with this, it has been demonstrated that many of the cardiovascular changes that first emerge during fetal life, including cardiac morphological changes, subclinical myocardial dysfunction, arterial remodeling, and impaired endothelial function, persist long-term [94]. 


\section{Preeclampsia}

Preeclampsia is a common hypertension-related pregnancy complication that is characterized by proteinuria and maternal organ dysfunction (such as renal insufficiency, liver, and placental dysfunction) post 20 weeks' gestation, affecting over $8 \%$ of pregnancies worldwide [ 9 , 100]. Preeclampsia results in utero-placental hypoxia, where the maternal blood oxygenation is normal, but the utero-placental circulation is impaired [101-103]. This can be induced via shallow placenta implantation due to restricted extravillous trophoblast invasion [104, 105]. Hypoperfusion of the placenta may result in growth restriction of the fetus and oligohydramnios, which often lead to preterm delivery of the fetus [106-109].

Exposure to a hypoxic intrauterine environment is associated with offspring vascular, metabolic, and cardiac modifications including aortic wall thickening, loss of NO vessel modulation, altered LV function, and increased susceptibility to ischemia and metabolic syndrome [110-112]. Recently, it has become apparent that offspring of hypertensive pregnancies may also have microvascular genotypic and phenotypic abnormalities that may persist beyond the perinatal period and into adulthood [113-116], which may account for their significantly lower threshold for the development of cardiovascular-related diseases [110]. While studies assessing the specific impact of preeclampsia on cardiac remodeling during the transition from fetal to neonatal life remain limited, further investigations are needed given that adolescents and young adults who were exposed to maternal preeclampsia display unique LV remodeling patterns including greater relative wall thickness, smaller internal cavity diameter, and lower longitudinal peak systolic strain $[112,117]$.

\section{Preterm Birth}

Preterm birth prior to 37 weeks' gestation is one of the leading causes of neonatal morbidity and mortality [118], though survival rates have continued to increase due to advances in prenatal and postnatal care [119-121]. It is a complex condition resulting from multiple etiologic pathways including preeclampsia, multiparity, and IUGR, though the majority of preterm births are spontaneous with unknown causes [122-124]. Given that premature infants begin extrauterine life prior to maturation of the fetal circulation, preterm neonates often possesses many immature functional and structural characteristics [3, 67]. The immature cardiovascular circulation increases susceptibility to a suboptimal fetal to neonatal transition $[8,52,125]$.
In addition, in preterm neonates, the immature DA muscular wall alongside elevated levels of circulating $\mathrm{PGE}_{2}$ and $\mathrm{NO}$ levels often results in an unresponsive ductal constriction and subsequent delayed ductal closure [6, $52,126]$. The DA remains open for $>4$ days of age in $10 \%$ of preterm neonates born between 30 and 37 weeks' gestation; $80 \%$ of those born between 25 and 28 weeks' gestation; and $90 \%$ of the those born between at 24 gestational weeks' gestation $[3,52]$. In term-born neonates, functional closure usually occurs within the first 3 days of postnatal life [127-129]. The FO can also remain patent in many premature infants and can have adverse consequences on pulmonary hyperperfusion and systemic hypoperfusion due to the increase in pulmonary flow, left-to-right shunting, and sustained ductal patency [3].

Bronchopulmonary dysplasia (BPD) is the most common morbidity of preterm infants born $<30$ weeks' gestation and is the most common lung disease of infancy [130]. The pathophysiology is characterized by interrupted lung development and dysmorphic pulmonary capillaries [131]. Over $30 \%$ of infants with BPD will develop pulmonary hypertension, including nearly $50 \%$ of infants with severe BPD $[132,133]$. Those who survive generally demonstrate resolution of pulmonary hypertension concordant with pulmonary vascular growth. However, longitudinal studies of BPD survivors have shown a life-long compromised pulmonary function, as well as an increased risk of RV dysfunction and possible recurrent pulmonary hypertension in adulthood [130].

Preterm birth, even in the absence of BPD and other related comorbidities, can affect myocardium structural development via altering cardiomyocyte maturation. In animal studies, the early exposure to a high resistance and hyperoxic ex utero environment causes the immature hyperplastic fetal cardiomyocytes to undergo significant hypertrophy, increased interstitial collagen deposition, and abnormal functional properties during postnatal development $[67,68]$. Similarly, recent studies in humans using echocardiography and MRI have highlighted that preterm infants display disproportionate postnatal hypertrophy, accompanied with a reduction in LV diastolic function and a persistent reduction in RV systolic function [10, 134, 135].

The consequences of exposure of the immature heart to the extrauterine environment persist beyond the neonatal period. Studies using echocardiography and MRI have highlighted the early impact on long-term cardiovascular development associated with prematurity, with potentially adverse remodeling in infants, children, adolescents, and young adults [10,112, 135-137]. In addition to the unique geometric and functional cardiac changes at rest, the pre- 
term cardiac phenotype is also characterized by a reduced myocardial functional reserve [138], which together may explain their increased risk of heart failure as early as childhood and into young adulthood [34, 139-141].

\section{Conclusion}

The development of the heart begins as early as the third week of gestation with the 4-chamber fetal heart formed by gestational week 7. It involves complex biochemical signals, interactions, and specification of myocardial progenitor cells and heart tube looping. The transition from the fetal to neonatal circulation is considered to be a period of intricate physiological, anatomical, and biochemical changes in the cardiovascular system. With a successful cardiopulmonary transition to the extrauterine environment, the fetal shunts are functionally modi- fied or eliminated, enabling independent life. Early and accurate diagnosis of fetal congenital heart defects and investigations into the impact of pregnancy complications on the offspring are now feasible with the usage of medical imaging tools including ultrasound and MRI. Identifying abnormalities in early cardiogenesis and the cardiovascular transitional physiology from fetal to neonatal life is essential for the immediate and long-term cardiovascular health risk of neonates.

\section{Disclosure Statement}

The authors declare no conflicts of interest.

\section{Funding Sources}

Dr Adam J. Lewandowski is funded by the British Heart Foundation (FS/18/3/33292).

\section{References}

1 Bulatovic I, Månsson-Broberg A, Sylvén C, Grinnemo KH. Human fetal cardiac progenitors: the role of stem cells and progenitors in the fetal and adult heart. Best Pract Res Clin Obstet Gynaecol. 2016 Feb;31:58-68.

2 Buckingham M, Meilhac S, Zaffran S. Building the mammalian heart from two sources of myocardial cells. Nat Rev Genet. 2005 Nov;6(11):826-35.

3 Finnemore A, Groves A. Physiology of the fetal and transitional circulation. Semin $\mathrm{Fe}$ tal Neonatal Med. 2015 Aug;20(4):210-6.

4 Morton SU, Brodsky D. Fetal Physiology and the Transition to Extrauterine Life. Clin Perinatol. 2016 Sep;43(3):395-407.

5 Berhrsin J, Gibson A. Cardiovascular system adaptation at birth. Paediatr Child Health. 2011;21(1):1-6.

6 Cavaliere TA. From Fetus to Neonate: A Sensational Journey. Newborn Infant Nurs Rev. 2016;16(2):43-7.

7 Cohen E, Wong FY, Horne RS, Yiallourou SR. Intrauterine growth restriction: impact on cardiovascular development and function throughout infancy. Pediatr Res. 2016 Jun;79(6):821-30

8 Wu TW, Azhibekov T, Seri I. Transitional Hemodynamics in Preterm Neonates: clinical Relevance. Pediatr Neonatol. 2016 Feb; 57(1):7-18.

9 Mol BW, Roberts CT, Thangaratinam S, Magee LA, de Groot CJ, Hofmeyr GJ. Preeclampsia. Lancet. 2016 Mar;387(10022): 999-1011.

10 Aye CY, Lewandowski AJ, Lamata P, Upton R, Davis E, Ohuma EO, et al. Disproportionate cardiac hypertrophy during early postnatal development in infants born preterm. $\mathrm{Pe}$ diatr Res. 2017 Jul;82(1):36-46.
11 Aye CY, Lewandowski AJ, Ohuma EO, Upton R, Packham A, Kenworthy Y, et al. TwoDimensional Echocardiography Estimates of Fetal Ventricular Mass throughout Gestation. Fetal Diagn Ther. 2018;44(1):18-27.

12 Saga Y, Kitajima S, Miyagawa-Tomita S. Mesp1 expression is the earliest sign of cardiovascular development. Trends Cardiovasc Med. 2000 Nov;10(8):345-52.

13 Paige SL, Plonowska K, Xu A, Wu SM. Molecular regulation of cardiomyocyte differentiation. Circ Res. 2015 Jan;116(2):341-53.

14 Bondue A, Lapouge G, Paulissen C, Semeraro C, Iacovino M, Kyba M, et al. Mesp1 acts as a master regulator of multipotent cardiovascular progenitor specification. Cell Stem Cell. 2008 Jul;3(1):69-84

15 Tirosh-Finkel L, Elhanany H, Rinon A, Tzahor E. Mesoderm progenitor cells of common origin contribute to the head musculature and the cardiac outflow tract. Development. 2006 May;133(10):1943-53.

16 Später D, Hansson EM, Zangi L, Chien KR. How to make a cardiomyocyte. Development. 2014 Dec;141(23):4418-31.

17 Chien KR, Domian IJ, Parker KK. Cardiogenesis and the complex biology of regenerative cardiovascular medicine. Science. 2008 Dec;322(5907):1494-7.

18 Lough J, Sugi Y. Endoderm and heart development. Dev Dyn. 2000 Apr;217(4):327-42.

19 Schlange T, Andrée B, Arnold HH, Brand T. BMP2 is required for early heart development during a distinct time period. Mech Dev. 2000 Mar;91(1-2):259-70.

20 Marvin MJ, Di Rocco G, Gardiner A, Bush $\mathrm{SM}$, Lassar AB. Inhibition of Wnt activity induces heart formation from posterior mesoderm. Genes Dev. 2001 Feb;15(3):316-27.
21 Lickert H, Kutsch S, Kanzler B, Tamai Y, Taketo MM, Kemler R. Formation of multiple hearts in mice following deletion of $\beta$-catenin in the embryonic endoderm. Dev Cell. 2002 Aug;3(2):171-81.

22 Kelly RG, Buckingham ME, Moorman AF. Heart fields and cardiac morphogenesis. Cold Spring Harb Perspect Med. 2014 Oct; 4(10):a015750.

23 Moore KL, Persaud TVN, Torchia MG. The Developing Human E-Book: Clinically Oriented Embryology With STUDENT CONSULT Online Access: Elsevier Health Sciences; 2011.

24 Armstrong MT, Lee DY, Armstrong PB Regulation of proliferation of the fetal myocardium. Dev Dyn. 2000 Oct;219(2): 226-36.

25 Christoffels VM, Smits GJ, Kispert A, Moorman AF. Development of the pacemaker tissues of the heart. Circ Res. 2010 Feb;106(2): $240-54$.

26 Hoogaars WM, Barnett P, Moorman AF, Christoffels VM. T-box factors determine cardiac design. Cell Mol Life Sci. 2007 Mar; 64(6):646-60

27 Moskowitz IP, Pizard A, Patel VV, Bruneau BG, Kim JB, Kupershmidt S, et al. The T-Box transcription factor $\mathrm{Tbx} 5$ is required for the patterning and maturation of the murine cardiac conduction system. Development. 2004 Aug;131(16):4107-16.

28 Hatcher CJ, Basson CT. Specification of the cardiac conduction system by transcription factors. Circ Res. 2009 Sep;105(7):620-30.

29 Rana MS, Christoffels VM, Moorman AF. A molecular and genetic outline of cardiac morphogenesis. Acta Physiol (Oxf). 2013 Apr;207(4):588-615. 
30 Singh MK, Christoffels VM, Dias JM, Trowe MO, Petry M, Schuster-Gossler K, et al. Tbx20 is essential for cardiac chamber differentiation and repression of Tbx2. Development. 2005 Jun;132(12):2697-707.

31 Gittenberger-de Groot AC, Calkoen EE, Poelmann RE, Bartelings MM, Jongbloed MR. Morphogenesis and molecular considerations on congenital cardiac septal defects. Ann Med. 2014 Dec;46(8):640-52.

32 Gittenberger-de Groot AC, Bartelings MM, Poelmann RE, Haak MC, Jongbloed MR. Embryology of the heart and its impact on understanding fetal and neonatal heart disease. Semin Fetal Neonatal Med. 2013 Oct; 18(5):237-44.

33 Latham GJ, Yung D. Current understanding and perioperative management of pediatric pulmonary hypertension. Paediatr Anaesth. 2019 May;29(5):441-56.

34 Yang YP, Li HR, Cao XM, Wang QX, Qiao CJ, Ya J. Second heart field and the development of the outflow tract in human embryonic heart. Dev Growth Differ. 2013 Apr; 55(3):359-67.

35 Lin YF, Swinburne I, Yelon D. Multiple influences of blood flow on cardiomyocyte hypertrophy in the embryonic zebrafish heart. Dev Biol. 2012 Feb;362(2):242-53.

36 Dietrich AC, Lombardo VA, Veerkamp J, Priller F, Abdelilah-Seyfried S. Blood flow and Bmp signaling control endocardial chamber morphogenesis. Dev Cell. 2014 Aug;30(4): 367-77.

37 Auman HJ, Coleman H, Riley HE, Olale F, Tsai HJ, Yelon D. Functional modulation of cardiac form through regionally confined cell shape changes. PLoS Biol. 2007 Mar; 5(3):e53.

38 Moorman A, Webb S, Brown NA, Lamers W, Anderson RH. Development of the heart: (1) formation of the cardiac chambers and arterial trunks. Heart. 2003 Jul;89(7):80614.

39 Samsa LA, Yang B, Liu J. Embryonic cardiac chamber maturation: Trabeculation, conduction, and cardiomyocyte proliferation. Am J Med Genet C Semin Med Genet. 2013 Aug;163C(3):157-68.

40 Ben-Shachar G, Arcilla RA, Lucas RV, Manasek FJ. Ventricular trabeculations in the chick embryo heart and their contribution to ventricular and muscular septal development. Circ Res. 1985 Nov;57(5):75966.

41 Grego-Bessa J, Luna-Zurita L, del Monte G, Bolós V, Melgar P, Arandilla A, et al. Notch signaling is essential for ventricular chamber development. Dev Cell. 2007 Mar;12(3):41529.

42 Rentschler S, Zander J, Meyers K, France D, Levine R, Porter G, et al. Neuregulin-1 promotes formation of the murine cardiac conduction system. Proc Natl Acad Sci USA. 2002 Aug;99(16):10464-9.

43 Tian X, Hu T, Zhang H, He L, Huang X, Liu $\mathrm{Q}$, et al. Vessel formation. De novo forma- tion of a distinct coronary vascular population in neonatal heart. Science. 2014 Jul; 345(6192):90-4.

44 Moorman AF, Christoffels VM. Development of the cardiac conduction system: a matter of chamber development. Novartis Found Symp. 2003;250:25-34.

45 Liu X, Gu X, Li Z, Li X, Li H, Chang J, et al. Neuregulin-1/erbB-activation improves cardiac function and survival in models of ischemic, dilated, and viral cardiomyopathy. J Am Coll Cardiol. 2006 Oct;48(7):1438-47.

46 Zhou B, Ma Q, Rajagopal S, Wu SM, Domian I, Rivera-Feliciano J, et al. Epicardial progenitors contribute to the cardiomyocyte lineage in the developing heart. Nature. 2008 Jul;454(7200):109-13.

47 Escot S, Blavet C, Härtle S, Duband JL, Fournier-Thibault C. Misregulation of SDF1-CXCR4 signaling impairs early cardiac neural crest cell migration leading to conotruncal defects. Circ Res. 2013 Aug; 113(5):505-16.

48 Keyte A, Hutson MR. The neural crest in cardiac congenital anomalies. Differentiation. 2012 Jul;84(1):25-40.

49 Hasten E, McDonald-McGinn DM, Crowley TB, Zackai E, Emanuel BS, Morrow BE, et al. Dysregulation of TBX1 dosage in the anterior heart field results in congenital heart disease resembling the 22q11.2 duplication syndrome. Hum Mol Genet. 2018 Jun;27(11):1847-57.

50 Blackburn S. Maternal, Fetal, \& Neonatal Physiology-E-Book: Elsevier Health Sciences; 2014.

51 Park MK. Fetal and perinatal circulation. Pediatric cardiology for practitioners. 2002, pp 93-7.

52 Gupta A, Paria A. Transition from fetus to neonate. Surgery. 2016;34(12):593-6.

53 Chatfield BA, McMurtry IF, Hall SL, Abman SH. Hemodynamic effects of endothelin-1 on ovine fetal pulmonary circulation. Am J Physiol. 1991 Jul;261(1 Pt 2):R182-7.

54 Paradis A, Zhang L. Role of endothelin in utero-placental circulation and fetal vascular function. Curr Vasc Pharmacol. 2013 Sep;11(5):594-605.

55 Di Tommaso M, Seravalli V, Martini I, La Torre P, Dani C. Blood gas values in clamped and unclamped umbilical cord at birth. Early Hum Dev. 2014 Sep;90(9):523-5.

56 Kotaska K, Urinovska R, Klapkova E, Prusa $\mathrm{R}$, Rob L, Binder T. Re-evaluation of cord blood arterial and venous reference ranges for $\mathrm{pH}, \mathrm{pO}(2), \mathrm{pCO}(2)$, according to spontaneous or cesarean delivery. J Clin Lab Anal. 2010;24(5):300-4.

57 Sharma A, Ford S, Calvert J. Adaptation for life: a review of neonatal physiology. Anaesth Intensive Care Med. 2014;15(3):8995.

58 Edelstone DI, Rudolph AM, Heymann MA Liver and ductus venosus blood flows in fetal lambs in utero. Circ Res. 1978 Mar;42(3): 426-33.
59 Reynolds P. Fetal to neonatal transition how does it take place? Surgery. 2013;31(3): 106-9.

60 Murphy PJ. The fetal circulation. Contin Educ Anaesth Crit Care Pain. 2005;5(4): 107-12.

61 Artman M, Mahony L, Teitel DF. Neonatal cardiology: McGraw-Hill, Medical Pub. Division; 2002.

62 Schneider DJ, Moore JW. Patent ductus arteriosus. Circulation. 2006 Oct;114(17) 1873-82.

63 Pildner von Steinburg S, Boulesteix AL, Lederer C, GrunowS, Schiermeier S, Hatzmann $\mathrm{W}$, et al. What is the "normal" fetal heart rate? PeerJ. 2013 Jun;1:e82.

64 Rasanen J, Wood DC, Weiner S, Ludomirski A, Huhta JC. Role of the pulmonary circulation in the distribution of human fetal cardiac output during the second half of pregnancy. Circulation. 1996 Sep;94(5):1068-73.

65 Mielke G, Benda N. Cardiac output and central distribution of blood flow in the human fetus. Circulation. 2001 Mar;103(12):1662-8.

66 Kiserud T. Physiology of the fetal circulation. Semin Fetal Neonatal Med. 2005 Dec; 10(6):493-503.

67 Bensley JG, Stacy VK, De Matteo R, Harding $\mathrm{R}$, Black MJ. Cardiac remodelling as a result of pre-term birth: implications for future cardiovascular disease. Eur Heart J. 2010 Aug;31(16):2058-66.

68 Bertagnolli M, Huyard F, Cloutier A, Anstey Z, Huot-Marchand JÉ, Fallaha C, et al Transient neonatal high oxygen exposure leads to early adult cardiac dysfunction, remodeling, and activation of the renin-angiotensin system. Hypertension. 2014 Jan; 63(1):143-50.

69 Manasek FJ. Mitosis in developing cardiac muscle. J Cell Biol. 1968 Apr;37(1):191-6.

70 Polinger IS. Growth and DNA synthesis in embryonic chick heart cells, in vivo and in vitro. Exp Cell Res. 1973 Feb;76(2):253-62.

71 Oparil S. Pathogenesis of ventricular hypertrophy. J Am Coll Cardiol. 1985 Jun;5(6 Suppl):57B-65B.

72 Jain A, El-khuffash AF, Kuipers BC, Mohamed A, Connelly KA, McNamara PJ, et al. Left ventricular function in healthy term neonates during the transitional period. J Pediatr. 2017 Mar;182:197-203.e2.

73 Jain A, Mohamed A, Kavanagh B, Shah PS, Kuipers BC, El-Khuffash A, et al. Cardiopulmonary Adaptation During First Day of Life in Human Neonates. J Pediatr. 2018 Sep;200: 50-57.e2.

74 Jain A, Mohamed A, El-Khuffash A, Connelly KA, Dallaire F, Jankov RP, et al. A comprehensive echocardiographic protocol for assessing neonatal right ventricular dimensions and function in the transitional period: normative data and $\mathrm{z}$ scores. J Am Soc Echocardiogr. 2014 Dec;27(12):1293-304.

75 Sinha SK, Donn SM. Fetal-to-neonatal maladaptation. Semin Fetal Neonatal Med. 2006 Jun;11(3):166-73. 
76 McGovern M, Miletin J. Cardiac Output Monitoring in Preterm Infants. Front Pediatr. 2018 Apr;6:84.

77 Lakshminrusimha S, Steinhorn RH, Wedgwood S, Savorgnan F, Nair J, Mathew B, et al. Pulmonary hemodynamics and vascular reactivity in asphyxiated term lambs resuscitated with 21 and $100 \%$ oxygen. J Appl Physiol (1985). 2011 Nov;111(5): 1441-7.

78 Lang JA, Pearson JT, Binder-Heschl C, Wallace MJ, Siew ML, Kitchen MJ, et al. Increase in pulmonary blood flow at birth: role of oxygen and lung aeration. J Physiol. 2016 Mar; 594(5):1389-98.

79 Groves AM, Kuschel CA, Knight DB, Skinner JR. Relationship between blood pressure and blood flow in newborn preterm infants. Arch Dis Child Fetal Neonatal Ed. 2008 Jan; 93(1):F29-32.

80 Rios DR, Bhattacharya S, Levy PT, McNamara PJ. Circulatory insufficiency and hypotension related to the ductus arteriosus in neonates. Front Pediatr. 2018 Mar;6:62.

81 Nagasawa H, Hamada C, Wakabayashi M, Nakagawa Y, Nomura S, Kohno Y. Time to spontaneous ductus arteriosus closure in full-term neonates. Open Heart. 2016 May; 3(1):e000413.

82 Tibby SM, Hatherill M, Marsh MJ, Murdoch IA. Clinicians' abilities to estimate cardiac index in ventilated children and infants. Arch Dis Child. 1997 Dec;77(6):516-8.

83 Quinn D, Cooper B, Clyman RI. Factors associated with permanent closure of the ductus arteriosus: a role for prolonged indomethacin therapy. Pediatrics. 2002 Jul;110(1 Pt 1):e10.

84 Rudolph A. Fetal circulation and cardiovascular adjustments after birth. Rudolph's Pediatrics. 20th ed. Stamford (CT): Appleton \& Lange; 1996. pp. 1409-13.

85 Reed KL. Fetal and neonatal cardiac assessment with Doppler. Semin Perinatol. 1987 Oct;11(4):347-56.

86 Friedman AH, Fahey JT. The transition from fetal to neonatal circulation: normal responses and implications for infants with heart disease. Semin Perinatol. 1993 Apr; 17(2):106-21.

87 Easter SR, Eckert LO, Boghossian N, Spencer R, Oteng-Ntim E, Ioannou C, et al.; Brighton Collaboration Fetal Growth Restriction Working Group. Fetal growth restriction: case definition \& guidelines for data collection, analysis, and presentation of immunization safety data. Vaccine. 2017 Dec;35(48 48 Pt A):6546-54.

88 Eleftheriades M, Creatsas G, Nicolaides K. Fetal growth restriction and postnatal development. Ann N Y Acad Sci. 2006 Dec; 1092(1):319-30

89 Alamri A, Alsulami A, Almahyawi R, Abushal R, Fida A. Predicting factors of recurrent deviated nasal septum after primary septoplasty in Jeddah, Saudi Arabia. Ann Afr Med. 2011;10:266-71.
90 Lee S, Walker SP. The role of ultrasound in the diagnosis and management of the growth restricted fetus. Australas J Ultrasound Med. 2010 Aug;13(3):31-6.

91 Morrow RJ, Adamson SL, Bull SB, Ritchie JW. Effect of placental embolization on the umbilical arterial velocity waveform in fetal sheep. Am J Obstet Gynecol. 1989 Oct; 161(4):1055-60.

92 Grubbs BH, Benirschke K, Korst LM, Llanes A, Yedigarova L, Chmait RH. Role of low placental share in twin-twin transfusion syndrome complicated by intrauterine growth restriction. Placenta. 2011 Aug; 32(8):616-8.

93 Sehgal A, Doctor T, Menahem S. Cardiac function and arterial biophysical properties in small for gestational age infants: postnatal manifestations of fetal programming. J Pediatr. 2013 Nov;163(5):1296-300.

94 Sarvari SI, Rodriguez-Lopez M, Nuñez-Garcia M, Sitges M, Sepulveda-Martinez A, Camara O, et al. Persistence of Cardiac Remodeling in Preadolescents With Fetal Growth Restriction. Circ Cardiovasc Imaging. 2017 Jan;10(1):10.

95 Crispi F, Hernandez-Andrade E, Pelsers MM, Plasencia W, Benavides-Serralde JA, Eixarch E, et al. Cardiac dysfunction and cell damage across clinical stages of severity in growth-restricted fetuses. Am J Obstet Gynecol. 2008 Sep;199(3):254.e1-8.

96 Fouzas S, Karatza AA, Davlouros PA, Chrysis D, Alexopoulos D, Mantagos S, et al. Neonatal cardiac dysfunction in intrauterine growth restriction. Pediatr Res. 2014 May; 75(5):651-7.

97 Iruretagoyena JI, Gonzalez-Tendero A, Garcia-Canadilla P, Amat-Roldan I, Torre I, Nadal A, Crispi F and Gratacos E. Cardiac dysfunction is associated with altered sarcomere ultrastructure in intrauterine growth restriction. Am J Obstet Gynecol. 2014 Jun; 210(6):550.e1-7.

98 Bubb KJ, Cock ML, Black MJ, Dodic M, Boon WM, Parkington HC, et al. Intrauterine growth restriction delays cardiomyocyte maturation and alters coronary artery function in the fetal sheep. J Physiol. 2007 Feb; 578(Pt 3):871-81.

99 Crispi F, Crovetto F, Gratacos E. Intrauterine growth restriction and later cardiovascular function. Early Hum Dev. 2018 Nov;126: 23-7.

100 Boardman H, Ormerod O, Leeson P. Haemodynamic changes in pregnancy: what can we learn from combined datasets? Heart. 2016 Apr;102(7):490-1.

101 Hutter D, Kingdom J, Jaeggi E. Causes and mechanisms of intrauterine hypoxia and its impact on the fetal cardiovascular system: a review. Int J Pediatr. 2010;2010:401323.

102 Lazdam M, de la Horra A, Diesch J, Kenworthy Y, Davis E, Lewandowski AJ, et al. Unique blood pressure characteristics in mother and offspring after early onset preeclampsia. $\mathrm{Hy}$ pertension. 2012 Nov;60(5):1338-45.
103 Lazdam M, Davis EF, Lewandowski AJ, Worton SA, Kenworthy Y, Kelly B, et al. Prevention of vascular dysfunction after preeclampsia: a potential long-term outcome measure and an emerging goal for treatment. J Pregnancy. 2012;2012:704146.

104 Mayhew TM, Ohadike C, Baker PN, Crocker IP, Mitchell C, Ong SS. Stereological investigation of placental morphology in pregnancies complicated by pre-eclampsia with and without intrauterine growth restriction. Placenta. 2003 Feb-Mar;24(2-3):219-26.

105 Meekins JW, Pijnenborg R, Hanssens M, McFadyen IR, van Asshe A. A study of placental bed spiral arteries and trophoblast invasion in normal and severe pre-eclamptic pregnancies. Br J Obstet Gynaecol. 1994 Aug;101(8): 669-74.

106 Bokslag A, van Weissenbruch M, Mol BW, de Groot CJ. Preeclampsia; short and longterm consequences for mother and neonate. Early Hum Dev. 2016 Nov; 102:47-50.

107 Odegård RA, Vatten LJ, Nilsen ST, Salvesen KÅ, Austgulen R. Preeclampsia and fetal growth. Obstet Gynecol. 2000 Dec;96(6): 950-5.

108 Harmon QE, Huang L, Umbach DM, Klungsøyr K, Engel SM, Magnus P, et al. Risk of fetal death with preeclampsia. Obstet Gynecol. 2015 Mar;125(3):628-35.

109 Kaufmann P, Black S, Huppertz B. Endovascular trophoblast invasion: implications for the pathogenesis of intrauterine growth retardation and preeclampsia. Biol Reprod. 2003 Jul;69(1):1-7.

110 Davis EF, Newton L, Lewandowski AJ, Lazdam M, Kelly BA, Kyriakou T, et al. Pre-eclampsia and offspring cardiovascular health: mechanistic insights from experimental studies. Clin Sci (Lond). 2012 Jul;123(2):5372.

111 Davis EF, Lazdam M, Lewandowski AJ, Worton SA, Kelly B, Kenworthy Y, et al. Cardiovascular risk factors in children and young adults born to preeclamptic pregnancies: a systematic review. Pediatrics. 2012 Jun;129(6):e1552-61.

112 Lewandowski AJ, Augustine D, Lamata P, Davis EF, Lazdam M, Francis J, et al. Preterm heart in adult life: cardiovascular magnetic resonance reveals distinct differences in left ventricular mass, geometry, and function. Circulation. 2013 Jan;127(2):197-206.

113 Yu GZ, Aye CY, Lewandowski AJ, Davis EF, Khoo CP, Newton L, et al. Association of Maternal Antiangiogenic Profile at Birth With Early Postnatal Loss of Microvascular Density in Offspring of Hypertensive Pregnancies. Hypertension. 2016 Sep;68(3):74959.

114 Lewandowski AJ, Davis EF, Yu G, Digby JE, Boardman H, Whitworth P, et al. Elevated blood pressure in preterm-born offspring associates with a distinct antiangiogenic state and microvascular abnormalities in adult life. Hypertension. 2015 Mar;65(3): 607-14. 
115 Jayet PY, Rimoldi SF, Stuber T, Salmòn CS, Hutter D, Rexhaj E, et al. Pulmonary and systemic vascular dysfunction in young offspring of mothers with preeclampsia. Circulation. 2010 Aug;122(5):488-94.

116 Yu GZ, Reilly S, Lewandowski AJ, Aye CYL, Simpson LJ, Newton L, et al. Neonatal MicroRNA Profile Determines Endothelial Function in Offspring of Hypertensive Pregnancies. Hypertension. 2018 Oct;72(4):937-45.

117 Timpka S, Macdonald-Wallis C, Hughes AD, Chaturvedi N, Franks PW, Lawlor DA, et al. Hypertensive Disorders of Pregnancy and Offspring Cardiac Structure and Function in Adolescence. J Am Heart Assoc. 2016 Oct;5(11):e003906.

118 Blencowe H, Cousens S, Oestergaard MZ, Chou D, Moller AB, Narwal R, et al. National, regional, and worldwide estimates of preterm birth rates in the year 2010 with time trends since 1990 for selected countries: a systematic analysis and implications. Lancet. 2012 Jun;379(9832):2162-72.

119 Burchert H, Lewandowski AJ. Preterm Birth Is a Novel, Independent Risk Factor for Altered Cardiac Remodeling and Early Heart Failure: Is it Time for a New Cardiomyopathy? Curr Treat Options Cardiovasc Med. 2019 Feb;21(2):8.

120 Lewandowski AJ, Lazdam M, Davis E, Kylintireas I, Diesch J, Francis J, et al. Shortterm exposure to exogenous lipids in premature infants and long-term changes in aortic and cardiac function. Arterioscler Thromb Vasc Biol. 2011 Sep;31(9):2125-35.

121 Kelly BA, Lewandowski AJ, Worton SA, Davis EF, Lazdam M, Francis J, et al. Antenatal glucocorticoid exposure and long-term alterations in aortic function and glucose metabolism. Pediatrics. 2012 May;129(5): e1282-90.

122 Esplin MS, Manuck TA, Varner MW, Christensen B, Biggio J, Bukowski R, et al. Cluster analysis of spontaneous preterm birth phenotypes identifies potential associations among preterm birth mechanisms. Am J Obstet Gynecol. 2015 Sep;213(3):429.e1-9.
123 Barros FC, Papageorghiou AT, Victora CG, Noble JA, Pang R, Iams J, et al.; International Fetal and Newborn Growth Consortium for the 21st Century. The distribution of clinical phenotypes of preterm birth syndrome: implications for prevention. JAMA Pediatr. 2015 Mar;169(3):220-9.

124 Lewandowski AJ, Leeson P. Preeclampsia, prematurity and cardiovascular health in adult life. Early Hum Dev. 2014 Nov;90(11): 725-9.

125 Aye CY, Lewandowski AJ, Oster J, Upton R, Davis E, Kenworthy Y, et al. Neonatal autonomic function after pregnancy complications and early cardiovascular development. Pediatr Res. 2018 Jul;84(1):85-91.

126 Broadhouse KM, Finnemore AE, Price AN Durighel G, Cox DJ, Edwards AD, et al. Cardiovascular magnetic resonance of cardiac function and myocardial mass in preterm infants: a preliminary study of the impact of patent ductus arteriosus. J Cardiovasc Magn Reson. 2014 Jul;16(1):54.

127 Gentile R, Stevenson G, Dooley T, Franklin D, Kawabori I, Pearlman A. Pulsed Doppler echocardiographic determination of time of ductal closure in normal newborn infants. J Pediatr. 1981 Mar;98(3):443-8.

128 Benitz WE; Committee on Fetus and Newborn, American Academy of Pediatrics. Patent ductus arteriosus in preterm infants. Pediatrics. 2016 Jan;137(1):e20153730.

129 Koch J, Hensley G, Roy L, Brown S, Ramaciotti C, Rosenfeld CR. Prevalence of spontaneous closure of the ductus arteriosus in neonates at a birth weight of 1000 grams or less. Pediatrics. 2006 Apr;117(4):1113-21.

130 Davidson LM, Berkelhamer SK. Bronchopulmonary dysplasia: chronic lung disease of infancy and long-term pulmonary outcomes. J Clin Med. 2017 Jan;6(1):4.

131 Jobe AJ. The new BPD: an arrest of lung development. Pediatr Res. 1999 Dec;46(6): 641-3.

132 Collaco JM, Romer LH, Stuart BD, Coulson JD, Everett AD, Lawson EE, et al. Frontiers in pulmonary hypertension in infants and children with bronchopulmonary dysplasia. Pediatr Pulmonol. 2012 Nov;47(11): 1042-53.

133 Krishnan U, Feinstein JA, Adatia I, Austin ED, Mullen MP, Hopper RK, et al. Evaluation and management of pulmonary hypertension in children with bronchopulmonary dysplasia. J Pediatr. 2017 Sep;188:24-34. e1.

134 Zecca E, Romagnoli C, Vento G, De Carolis MP, De Rosa G, Tortorolo G. Left ventricle dimensions in preterm infants during the first month of life. Eur J Pediatr. 2001 Apr; 160(4):227-30.

135 Cox DJ, Bai W, Price AN, Edwards AD, Rueckert D, Groves AM. Ventricular remodeling in preterm infants: computational cardiac magnetic resonance atlasing shows significant early remodeling of the left ventricle. Pediatr Res. 2019 May;85(6):807-15.

136 Lewandowski AJ, Bradlow WM, Augustine D, Davis EF, Francis J, Singhal A, et al. Right ventricular systolic dysfunction in young adults born preterm. Circulation. 2013 Aug; 128(7):713-20

137 Lewandowski AJ, Lamata P, Francis JM, Piechnik SK, Ferreira VM, Boardman H, et al. Breast milk consumption in preterm neonates and cardiac shape in adulthood. Pediatrics. $2016 \mathrm{Jul} ; 138(1): 138$.

138 Huckstep OJ, Williamson W, Telles F, Burchert H, Bertagnolli M, Herdman C, et al. Physiological stress elicits impaired left ventricular function in preterm-born adults. J Am Coll Cardiol. 2018 Mar; 71(12):1347-56.

139 Carr H, Cnattingius S, Granath F, Ludvigsson JF, Edstedt Bonamy AK. Preterm Birth and Risk of Heart Failure Up to Early Adulthood. J Am Coll Cardiol. 2017 May;69(21): 2634-42.

140 Lewandowski AJ. The preterm heart: a unique cardiomyopathy? Pediatr Res. 2019 May;85(6):738-9.

141 Leeson P, Lewandowski AJ. A New Risk Factor for Early Heart Failure: preterm Birth. J Am Coll Cardiol. 2017 May;69(21):2643-5. 